\title{
Financial Conflict Messages and Marital Satisfaction: The Mediating Role of Financial Communication Satisfaction
}

\author{
Samantha J. Shebib ${ }^{1 *}$, William R. Cupach ${ }^{2}$ \\ ${ }^{1}$ Department of Communication, Michigan State University, East Lansing, MI, USA \\ ${ }^{2}$ School of Communication, Illinois State University, Normal, IL, USA \\ Email: *shebibsa@msu.edu
}

How to cite this paper: Shebib, S. J., \& Cupach, W. R. (2018). Financial Conflict Messages and Marital Satisfaction: The Mediating Role of Financial Communication Satisfaction. Psychology, 9, 144-163. https://doi.org/10.4236/psych.2018.91010

Received: November 2, 2017

Accepted: January 27, 2018

Published: January 30, 2018

Copyright (c) 2018 by authors and Scientific Research Publishing Inc. This work is licensed under the Creative Commons Attribution International License (CC BY 4.0).

http://creativecommons.org/licenses/by/4.0/

\section{c) (i) Open Access}

\begin{abstract}
Conflict over money is one of the most commonly cited topics of marital disagreements (Oggins, 2003). However, little empirical research has examined how marital couples communicate about financial issues, specifically, and how these financial communication messages contribute to, or detract from, marital satisfaction. Knowledge about how couples communicate regarding financial issues is of significance to conflict scholars because it would allow us to understand the potential detriments of certain financial conflict message patterns and how these patterns ultimately affect one's marital satisfaction. Married individuals (not marital dyads) were recruited online to participate in an online survey about their financial communication patterns within his or her marriage. In the present study of 326 married individuals, we found that constructive financial conflict messages were positively associated with financial harmony, marital satisfaction, and financial communication satisfaction. Destructive financial conflict messages, the demand-withdraw financial conflict message pattern, and mutually avoiding financial conflict were each negatively associated with financial harmony, marital satisfaction, and financial communication satisfaction. In addition, financial communication satisfaction mediated the relationship between each of the financial conflict message patterns and marital satisfaction. The current study lays empirical groundwork for developing a theoretical framework for understanding marital interaction patterns and the effects these patterns have on marital satisfaction.
\end{abstract}

\section{Keywords}

Marital Relationships, Family Psychology, Interpersonal Communication, Financial Communication, Financial Communication Satisfaction, Financial Conflict, Marital Conflict, Marital Satisfaction, Financial Harmony 


\section{Introduction}

Financial issues play a significant role in marital relationships. Previous research has identified money as a main source of conflict within marriages (e.g., Blumstein \& Schwartz, 1983; Oggins, 2003). Because financial decisions occur routinely and cannot be ignored, it is not uncommon for financial disagreements to occur frequently in marriages (Blumstein \& Schwartz, 1983). These financial disagreements have the potential to lead marital partners to engage in heated conflict (Dew \& Dakin, 2011). Despite the importance of financial issues, marital couples are often reluctant to communicate about them (Atwood, 2012).

One reason discussing finances is seen as taboo is because financial conflict carries a negative reputation compared to other types of marital disagreements (Britt, Huston, \& Durband, 2010). For example, Papp, Cummings, and GoekeMorey (2009) found that conflict over money was more likely to remain unresolved compared to other marital conflict issues. They also found marital partners experienced more anxiety, trepidation, distress, and unhappiness regarding conflict about money compared to other disagreements.

Using data from the National Survey of Families and Households (NSFH), Dew, Britt, and Huston (2012) found that financial disagreements were the strongest predictors of divorce relative to other types of marital arguments, such as chores, time spent together, sex, and in-laws. Of particular interest, Dew and colleagues highlighted the importance of the financial argument's intensity contributing to a higher likelihood of divorcing; that is, the more intense the financial arguments were, the more likely the couple would divorce. This is consistent with Gottman's (1994) evidence that the way in which couples communicate during conflict is more strongly associated with marital dissolution than the mere frequency of having disagreements.

This literature raises the question of how marital partners are specifically communicating about financial issues. If financial conflicts can erode marital relationships, then it seems reasonable to suggest functional and constructive communication during financial conversations would help to minimize the negative consequences. Several studies have acknowledged the key to managing finances is for partners to collaboratively and openly discuss financial issues (e.g., Romo, 2011). More specifically, Archuleta, Britt, Tonn, and Grable (2011) argued that the manner in which couples manage financial stressors may have a greater influence on financial satisfaction than the actual stressors. To the extent communication about financial stressors diminishes anxiety, it may enhance feelings of financial satisfaction. Little empirical work to date has directly addressed the specific manner in which marital couples communicate about financial issues. Therefore, the current study is designed to explore how methods of handling financial disagreements contribute to, or detract from, marital satisfaction. Given the centrality of financial issues in marriage, knowing the relatively more effective approaches to communicating about finances can ultimately enhance marital happiness and stability. 
In the review that follows, we summarize the primary types of messages used by couples to manage conflict. Next we explore how financial harmony is likely to be associated with each of the types of conflict messages. Then we make the case that satisfaction with communicating about financial issues in marriage mediates the relationship between financial conflict messages and marital satisfaction.

\section{Types of Conflict Messages}

Conflict is inescapable in marriages. Although conflict often carries a negative connotation, not all conflict is bad. The way in which people handle conflict affects the longevity of their close relationships (Gottman, 1979; 1994). There are numerous ways to classify and characterize behaviors enacted during conflict (Cupach, 2015). One common approach distinguishes three strategic types of conflict behavior (e.g., Canary \& Cupach, 1988; Putnam \& Wilson, 1982; Sillars, Coletti, Parry, \& Rogers, 1982). Although some authors referring to the same categories employ different labels, the three types can be referred to as: constructive, destructive, and avoidance conflict behaviors.

Constructive conflict behaviors include collaborative, cooperative, problem-oriented, supportive, and compromising tactics (Canary \& Cupach, 1988). Also referred to as integrative (Sillars et al., 1982), positive (Wilmarth, Nielsen, \& Futris, 2014), and prosocial (Roloff, 1976), constructive behaviors involve active engagement in a conflict and generally exhibit a positive tone (Cupach, 2015). When utilizing constructive strategies, couples manage disagreements in a way that promotes trust and is mutually satisfying (Deutsch, 1973).

Destructive conflict behaviors involve active confrontation with a negative tone (Cupach, 2015). These behaviors have also been referred to as distributive (Sillars, 1980), negative (Wilmarth et al., 2014), and anti-social (Roloff, 1976). Destructive conflict behaviors include competitive fighting, controlling behaviors, or being passive aggressive. Insults, criticisms, and defensiveness also represent manifestations of destructive conflict (e.g., Gottman, 1979; 1994). Patterns of destructive conflict typically involve reciprocation of negative affect between partners (Gottman, 1994) and escalation of conflict intensity, which typically leaves the conflicting partners dissatisfied with the aftermath (Deutsch, 1973).

Avoidance is a passive and non-confrontational pattern of conflict and is characterized by not directly discussing the problem or issue with the person, hinting, joking, letting the issue resolve itself, topic shifts, noncommittal questions and statements, evasive remarks, and direct and implicit denial (Sillars, 1980).

In addition to the constructive, destructive, and avoidance conflict messages, the literature identifies a fourth distinctive conflict pattern of demand-withdraw. The demand-withdraw pattern is a commonly reoccurring interaction pattern where "one spouse pressures the other with demands, complaints, and criticisms, while the partner withdraws with defensiveness and passive inaction" 
(Christensen \& Shenk, 1991, p. 458). This pattern of communication combines elements of both avoidance and destructive confrontation. Demand-withdraw would seem to be quite different in its form and function compared to mutual avoidance of a conflict topic, and it has been distinguished from other destructive conflict patterns such as criticize-defend (Futris, Campbell, Nielsen, \& Burwell, 2010; Gottman, 1994).

Research on conflict behaviors in marriage is copious. However, it typically does not focus on a specific topical domain such as finances. Even studies that examine conflict in the context of financial distress have only measured general conflict tendencies in marital relationships, but not communication specifically during financial conflict (e.g., Dew \& Dakin, 2011). This is problematic because conclusions regarding the relationship between financial communication and marital outcomes are inferred, but not empirically tested. A person's general orientation to conflict across topics with a partner may not correspond to communication patterns when discussing finances. For example, one may generally avoid conflict with a partner on a day-to-day basis, but communicate in a belligerent and destructive manner when discussing finances. In order to demonstrate more precisely that communication about finances is associated with marital outcomes (and other variables), it is essential to measure financial conflict messages more directly.

\section{Financial Harmony and Financial Conflict Messages}

Financial harmony refers to how "in sync" marital spouses' beliefs and practices are regarding money (Rick, Small, \& Finkel, 2011). In other words, financial harmony represents agreement between partners about financial issues. Financial disharmony occurs when couples have frequent and distressing disagreements about financial issues. Rick and colleagues found that spouses who had dissimilar spending patterns (i.e., one partner was a "spendthrift," while the other partner was a "tightwad") tended to have more conflict about finances, which in turn, predicted diminished marital well-being.

No research, to date, has examined how financial harmony (or lack thereof) is associated with the various types of conflict messages when financial disagreements arise. However, we can predict that when spouses are in financial harmony they are generally in agreement with how to manage money, which likely predisposes them to communicate in ways that resolve differences that arise. They may also be more likely to communicate in constructive ways because they already have a preconceived notion of their spouse's beliefs about money, and because their spouse's beliefs are in line with theirs, they constructively and proactively deal with their financial issues.

When couples are not in sync and do not agree with how to handle finances, individuals know their spouse's view is contrary to their own. This may lead individuals to communicate in destructive ways as they push their position on the financial issue that is in contention. This can cause unresolved issues, which in 
turn, exacerbates differences that can lead to more destructive communication tendencies.

In regard to the demand-withdraw pattern, when one individual is demanding to discuss a financial issue and the other spouse circumvents the discussion, it may be that these individuals do not agree on how they are handling finances. It is also possible that the demanding partner is seeking compliance, while the avoiding partner wants more time to think about the issue. If one spouse is demanding and the other partner is withdrawing regarding financial matters, they are not likely to be financially harmonized. Based on the preceding discussion, three hypotheses are proposed:

$\mathrm{H}_{1}$ : Financial harmony is positively associated with constructive financial conflict messages.

$\mathrm{H}_{2}$ : Financial harmony is negatively associated with destructive financial conflict messages.

$\mathrm{H}_{3}$ : Financial harmony is negatively associated with the demand-withdraw financial conflict message pattern.

In terms of conflict avoidance, mutual avoidance may in fact be a reflection of spouses being financially in sync with each other. Alternatively, they could be so out of sync that they do not even discuss the financial issues with each other, or partners may have decided to "agree to disagree" about certain financial issues. Therefore, mutual avoidance of conflict issues may or may not reflect financial harmony. Since the effects of financial harmony and mutually avoiding financial conflict messages are ambivalent, a research question is posed:

$\mathrm{RQ}_{1}$ : What is the relationship between financial harmony and mutually avoiding financial conflict messages?

\section{Financial Conflict Messages and Marital Satisfaction}

Previous research has documented how conflict messages are generally related to marital or relational satisfaction. However, scant scholarly attention has been devoted to understanding how marital partners are communicating about a specific conflict topic, such as finances, and the impact these conflict messages would have on marital satisfaction. Given the centrality of financial issues in marriage, knowing the relatively more effective approaches to communicating about finances can ultimately enhance marital satisfaction and commitment.

\subsection{Constructive and Destructive Financial Conflict Messages}

Several studies have consistently demonstrated that constructive conflict messages are positively associated with relational satisfaction, whereas destructive messages are negatively associated with relational satisfaction (e.g., Canary \& Cupach, 1988; Canary, Cupach, \& Serpe, 2001; Futris et al., 2010; Gottman, 1994; Sillars, 1980). For example, Ting-Toomey (1983) coded 34 marital couples' verbal exchanges of conflict when spouses were engaging in disagreements with each other. She found a positive association between constructive messages (la- 
beled integrative) and marital satisfaction, and a negative association between destructive conflict messages (labeled disintegrative) and marital satisfaction.

Wilmarth and colleagues (2014) investigated marital communication patterns in the context of financial wellness and relational satisfaction. Constructive conflict communication (referred to as positive) consisted of mutually discussing, expressing, and negotiating conversations about a conflict topic. Destructive conflict communication (referred to as negative) consisted of mutually blaming, criticizing, and defending behaviors. Wilmarth and colleagues found constructive communication was positively associated with relational satisfaction. Additionally, their findings revealed that financial distress contributed to destructive communication. Destructive communication, in turn, was negatively associated with relational satisfaction. In fact, the destructive communication mediated the connection between financial distress and relational satisfaction. It is important to note that the communication patterns measured in this study were not specific to financial disagreements. Rather, Wilmarth and colleagues assessed the manner in which couples managed disagreements of any kind, in general. The present study makes predictions comparable to the findings of Wilmarth et al., such that destructive communication about financial issues in particular will be problematic for marital partners, whereas engaging in constructive communication will be more satisfying for couples. Specifically,

$\mathrm{H}_{4}$ : Constructive financial conflict messages are positively associated with marital satisfaction.

$\mathrm{H}_{5}$ : Destructive financial conflict messages are negatively associated with marital satisfaction.

\subsection{The Demand-Withdraw Financial Conflict Message Pattern}

Considerable evidence has supported the notion that couples who exhibit demand-withdraw patterns of conflict experience more dissatisfaction in their marriage (e.g., Christensen \& Shenk, 1991; Futris et al., 2010; Papp, Kouros, \& Cummings, 2009). Schrodt, Witt, and Shimkowski (2014) conducted a meta-analysis of 74 studies that examined the demand-withdraw pattern and relational outcomes. Schrodt and colleagues meta-analysis revealed that the demand-withdraw pattern showed a "moderate and meaningful" (p. 47) relationship to a variety of negative relational outcomes. More specifically, the demand-withdraw pattern was significantly, negatively associated with relational satisfaction, exhibiting an effect size of $r=0.36$ across the 74 empirical reports. The demand-withdraw pattern was also associated with an increase in violence, aggression, and mental health symptoms.

Another study (not included in the meta-analysis reported above) conducted by Wilmarth et al. (2014) found that married couples experiencing financial distress (i.e., the lack of financial wellness) were more likely to report demand-withdraw communication patterns in their marriage. Moreover, the demand-withdraw tendencies were negatively associated with marital quality. The 
demand-withdraw pattern of communication mediated the negative association between financial distress and marital quality. It is noteworthy that this study measured participant's perceptions of how they and their spouse communicate during conflict on any issue. Again, it was not specific to the communication that occurs during financial conversations. General conflict communication patterns were assessed rather than conflict patterns specific to financial discussions. Therefore, the current study will extend prior research by assessing the ways in which individuals manage disagreements about financial issues in particular. We hypothesize:

$\mathrm{H}_{6}$ : The demand-withdraw financial message pattern is negatively associated with marital satisfaction.

\subsection{Mutually Avoiding Financial Conflict}

Scholars have identified avoidance as a conflict pattern that can have either negative or positive effects on a relationship (e.g., Roloff \& Ifert, 2000). Conflict avoidance may be beneficial in certain episodes of conflict, such as when one or both partners require a "cooling off" period to prevent hostile escalation, or when the conflict issue is of trivial importance. However, evidence has linked chronic conflict avoidance to relational dissatisfaction (e.g., Smith, Heaven, \& Ciarrochi, 2008). As indicated earlier, mutual avoidance may signal that partners are or are not in harmony with regard to financial issues. Given the equivocal nature of conflict avoidance, a research question is posed:

$\mathrm{RQ}_{2}$ : What is the relationship between mutually avoiding financial conflict messages and marital satisfaction?

\section{Financial Communication Satisfaction as a Mediator}

One reason that constructive communication is associated with positive relational outcomes such as marital satisfaction is because partners feel more satisfied with the interaction when they engage in constructive communication. According to Hecht, Sereno, and Spitzberg (1984), "communication satisfaction is the positive emotion we feel after successful and fulfilling communicative interactions" (p. 376). Several studies have found an association between constructive conflict behavior and communication satisfaction (e.g., Canary \& Spitzberg, 1989; Newton \& Burgoon, 1990). For instance, Canary and Cupach (1988) studied dyads including romantic partners, friends, and roommates. Each pair decided on a recent conflict on which they would report, and then each dyad member independently completed a survey about the conflict episode. Results showed that partner's use of constructive conflict behaviors was positively associated with one's own communication satisfaction, whereas partner's use of destructive strategies was negatively associated with one's own communication satisfaction. Moreover, communication satisfaction mediated the association between conflict behaviors and relational outcomes such as trust, intimacy and relational satisfaction. In other words, constructive communication was positively 
associated with communication satisfaction, which in turn, predicted positive relational outcomes. Destructive conflict communication was negatively associated with communication satisfaction, which in turn, was associated with negative relational outcomes. Canary et al. (2001) replicated these findings with a sample of marital couples, using an index of relational quality that included trust and liking/loving of partner. Again, communication satisfaction translated the positive effects of constructive conflict behaviors into higher levers of relational quality, and conveyed the negative effects of destructive behaviors into lower levels of relational quality.

In the current study, it is expected that results analogous to those just summarized will be exhibited when examining conflict specifically about financial issues. Thus, the following hypotheses are proposed:

$\mathrm{H}_{7}$ : Constructive financial conflict messages are positively associated with financial communication satisfaction.

$\mathrm{H}_{8}$ : Destructive financial conflict messages are negatively associated with financial communication satisfaction.

$\mathrm{H}_{9}$ : The demand-withdraw financial conflict message pattern is negatively associated with financial communication satisfaction.

$\mathrm{H}_{10}$ : Financial communication satisfaction is positively associated with marital satisfaction.

$\mathrm{H}_{11}$ : Financial communication satisfaction mediates the association between financial conflict messages and marital satisfaction.

Since the effects of mutual avoidance on communication and relational satisfaction are more equivocal, a research question is posed:

$\mathrm{RQ}_{3}$ : What is the relationship between mutually avoiding financial conflict messages and financial communication satisfaction?

\section{Methods}

\subsection{Participants}

The sample consisted of 326 married individuals. Eleven individuals (3\%) skipped answering the demographic questions at the end of the survey; the following demographic statistics exclude these individuals. Composition of the sample was $76.5 \%$ female and $23.5 \%$ male. In terms of the participant's spouse, $75.2 \%$ were male and $24.8 \%$ were female. The mean age was $39.89(S D=13.21)$, ranging from 22 to 81 years old. Participants primarily identified themselves as Caucasian/White (92.4\%), followed by Hispanic/Latino (2.5\%), Asian (1.6\%), Multiracial (1.3\%), other (1\%), Pacific Islander (0.6\%), African American $(0.3 \%)$, and $0.3 \%$ preferred not to answer. Educationally, the greatest number of participants stated they obtained a Bachelor's degree (35.3\%), followed by Master's degree (22.4\%), completed some college (9.6\%), Ph.D., law or medical degree $(9.6 \%)$, completed some postgraduate $(9 \%)$, associate degree $(8 \%)$, high school degree $(4.2 \%)$, other advanced degree beyond a Master's degree (1.3\%), and less than a high school degree $(0.6 \%)$. Growing up, the majority of partici- 
pants identified their socioeconomic class as middle-class (45.5\%), followed by lower middle/working class (24.8\%), upper-middle class (24.2\%), poor (2.9\%), and wealthy (2.5\%). Participants indicated which interval most closely identified their total household income before taxes during the past 12 months: less than $\$ 25,000$ (2.3\%), $\$ 25,000$ to $\$ 34,999$ (5.9\%), $\$ 35,000$ to $\$ 49,999$ (6.9\%), $\$ 50,000$ to $\$ 74,999$ (10.8\%), $\$ 75,000$ to $\$ 99,999$ (19.3\%), $\$ 100,000$ to $\$ 149,999$ (24.5\%), $\$ 150,000$ to $\$ 199,999$ (12.4\%), and $\$ 200,000$ or more (18\%).

\subsection{Procedures}

Married individuals (not marital dyads) were recruited in three ways. First, participants were recruited from the researchers' Facebook pages. Second, participants were recruited with an announcement in a national professional association's listerv. Finally, participants were able to self-select to participate in the survey from a weekly e-newsletter that contains information about events for families within a local community in the Midwest. To qualify for this study, participants had to be at least 18 years of age and currently married for a minimum of six months. After they agreed to the informed consent electronically, participants were then directed to the anonymous web based questionnaire.

\subsection{Measurements}

Financial wellness. Since financial wellness is negatively associated with the occurrence of financial conflict (Wilmarth et al., 2014) and positively associated with marital satisfaction (Archuleta et al., 2011), it is included in this study as a control variable. Financial wellness was assessed using the Personal Financial Wellness (PFW) scale (Prawitz et al., 2006), which consisted of eight self-report items that subjectively measure one's financial distress and financial wellness within one's marriage. Items included "What do you feel is the level of your financial stress today?" and "How stressed do you feel about your personal finances in general?" These items were rated along a 10-point Likert-type scale. Consistent with Prawitz and colleagues, the PFW scale was reliable $(\alpha=0.94)$.

Financial harmony. Financial harmony was assessed using Rick et al.'s (2011) 10 -item measure. Items included "When it comes to our finances, my spouse and I see eye to eye" and "My spouse is satisfied with my attitudes towards money." Agreement was rated on a Likert-type scale ranging from one to seven. Consistent with Rick and colleagues, the combined items were reliable ( $\alpha=0.90)$.

Financial conflict messages. Financial conflict messages were assessed using an adapted version of Christensen and Heavey's (1990) communication patterns questionnaire-short form (CPQ-SF). The CPQ-SF consisted of eleven items comprised of four subscales (constructive, destructive, demand-withdraw, and mutual avoidance). Scale items were adapted to focus on messages during financial conflict, rather than disagreements in general. Items were measured on a Likert-type scale ranging from one to seven. Constructive financial conflict messages were characterized as proactively discussing and dealing with financial 
issues. Three items were used to assess this subscale. The items included "Both spouses express feelings to each other about the financial matter in question" and "Both spouses suggest possible solutions and compromises to the financial issue." Scale reliability was $\alpha=0.78$.

Destructive financial conflict messages were operationalized when both spouses mutually blame, accuse, or criticize each other. A total of three items assessed the subscale of destructive financial conflict messages. Items included "Both spouses blame, accuse, or criticize each other when conflicting over financial obligations" and "You criticize while your spouse defends him or herself." Scale reliability was $\alpha=0.81$.

The demand-withdraw financial conflict pattern is manifested when one spouse insists on discussing the conflicting financial matter, while the other spouse evades the conversation. This subscale had four items. These included "Your spouse pressures, nags, demands you, while you withdraw, become silent, and refuse to discuss the financial matter further" and "You try to start a discussion about the financial problem, while your spouse tries to avoid the financial discussion." In the current study, the demand-withdraw financial conflict pattern reliability was $\alpha=0.67$.

Finally, mutually avoiding financial messages typified when both spouses circumvent talking about finances. The CPQ-SF contained only one item assessing the mutual avoidance subscale: "Both you and your spouse will avoid discussing the financial topic." In addition to this item, two new items were devised for the current study to assess mutual avoidance: "Both you and your spouse steer clear of discussing financial issues" and "Both you and your spouse shy away from discussing financial disagreements." Reliability was $\alpha=0.87$.

Marital satisfaction. Marital satisfaction was measured using Hendrick's (1988) seven-item relationship assessment scale, which was adapted to reflect marriages. Items included "In general, how satisfied are you with your marriage," and "How well does your spouse meet your needs?" Items were assessed along a 7-point Likert-type scale. Scale reliability was $\alpha=0.90$.

Financial communication satisfaction. Six items were devised to measure participants' satisfaction with financial communication with their spouse. Items included "I am satisfied with the way in which we communicate about finances in my marriage" and "I am happy with the way we negotiate financial disagreements." These items were assessed along a 7-point Likert-type scale. The scale reliability was $\alpha=0.97$.

\section{Results}

Hypotheses 1 - 10 and research questions 1 - 3 were tested by computing second-order partial correlation coefficients, controlling for the potentially confounding effects of financial wellness and income. Financial wellness has previously been associated with both conflict behavior and relational satisfaction (e.g., Wilmarth et al., 2014). Similarly, income may influence marital satisfaction 
insofar as lower income can translate into a stressor in a marriage. One-tailed probabilities were employed for hypotheses and two-tailed probabilities were used for research questions.

\subsection{Financial Harmony}

Hypotheses 1 - 3 and research question 1 concerned the relationships between financial harmony and the different financial conflict messages. As predicted, financial harmony was positively association with constructive financial conflict messages, $\operatorname{pr}(302)=0.59, p<0.001$, thus the data are consistent with the hypothesis. Consistent with hypotheses 2 and 3, financial harmony was negatively associated with destructive financial conflict messages, $\operatorname{pr}(302)=-0.63, p<$ 0.001 , and the demand-withdraw financial conflict message pattern, $\operatorname{pr}(302)=$ $-0.69, p<0.001$. In response to research question 1 , financial harmony was also negatively associated with mutually avoiding financial conflict messages, $\operatorname{pr}(302)$ $=-0.62, p<0.001$.

\subsection{Marital Satisfaction}

Hypotheses 4 - 6 and research question 2 pertained to the relationships between the four financial conflict messages and marital satisfaction. Constructive financial conflict messages were positively associated with marital satisfaction, $\operatorname{pr}(302)=0.42, p<0.001$. Destructive financial conflict messages, $\operatorname{pr}(302)=$ $-0.46, p<0.001$, and the demand-withdraw financial message pattern, $\operatorname{pr}(302)=$ $-0.47, p<0.001$, were both negatively associated with marital satisfaction. These findings indicate that the data are consistent with hypotheses $4-6$, respectively. In addressing research question 2 , mutually avoiding financial conflict messages demonstrated a negative association with marital satisfaction, $\operatorname{pr}(302)=-0.30, p$ $<0.001$.

\subsection{Financial Communication Satisfaction}

Hypothesis 7 - 9 and research question 3 explored the associations between financial conflict messages and financial communication satisfaction. As predicted, constructive financial conflict messages were positively associated with financial communication satisfaction, $\operatorname{pr}(302)=0.76, p<0.001$. Destructive financial conflict messages were negatively associated with financial communication satisfaction, $\operatorname{pr}(302)=-0.57, p<0.001$. The demand-withdraw financial conflict message pattern was negatively associated with financial communication satisfaction, $\operatorname{pr}(302)=-0.72, p<0.001$. These findings indicate that the data are consistent with hypotheses 7 - 9. In response to research question 3, mutually avoiding financial conflict messages showed a negative relationship with financial communication satisfaction, $\operatorname{pr}(302)=-0.67, p<0.001$.

Hypothesis 10 predicted a positive association between financial communication satisfaction and marital satisfaction. The partial correlation revealed a significant relationship between these variables, $\operatorname{pr}(302)=0.49, p<0.001$. Thus, the 
data are consistent with the hypothesis.

\subsection{Financial Communication Satisfaction as a Mediator}

Hypothesis 11 predicted that financial communication satisfaction would mediate the association between financial conflict messages and marital satisfaction. To test this hypothesis, Hayes (2013) PROCESS macro for SPSS was employed. This permits a test of the proposed mechanism by which financial conflict messages influence marital satisfaction, specifically through the mediating variable of financial communication satisfaction (Hayes, 2009; Preacher \& Hayes, 2008). An indirect effect on marital satisfaction, as carried by the mediator of financial communication satisfaction, was tested separately for each of the four financial conflict message predictors. In each case, a bias-corrected bootstrap confidence interval (95\%) based on 10,000 bootstrap samples was computed. Unstandardized path coefficients are reported in text and tables. Effect sizes for indirect effects were estimated with $\kappa^{2}$ (Preacher \& Kelley, 2011) and $R_{\text {med }}^{2}$ (Fairchild, MacKinnon, Toborga, \& Taylor, 2009).

Constructive financial conflict messages positively predicted financial communication satisfaction, $a=1.03,95 \%$ CI $[0.94,1.11]$, and financial communication satisfaction positively predicted marital satisfaction, $b=0.29,95 \% \mathrm{CI}[0.20$, 0.39]. The indirect effect of constructive financial conflict messages on marital satisfaction was significant, $a b=0.30,95 \% \mathrm{CI}[0.18,0.44], \kappa^{2}=0.27,95 \% \mathrm{CI}$ $[0.16,0.36], R_{\text {med }}^{2}=.24,95 \%$ CI $[0.15,0.33]$. The association between dealing with financial discussions constructively and marital satisfaction was mediated by financial communication satisfaction (see Table 1).

Destructive financial conflict messages negatively predicted financial communication satisfaction, $a=-0.73,95 \%$ CI $[-0.83,-0.64]$, while financial communication satisfaction positively predicted marital satisfaction, $b=0.24,95 \% \mathrm{CI}[0.17$, 0.31]. The indirect effect of destructive financial conflict messages on marital satisfaction was significant, $a b=-.18,95 \%$ CI $[-0.26,-0.12], \kappa^{2}=0.23,95 \% \mathrm{CI}$

Table 1. Model coefficients for constructive financial conflict messages.

\begin{tabular}{|c|c|c|c|c|c|c|c|c|}
\hline \multirow[b]{3}{*}{ Antecedent } & & \multicolumn{7}{|c|}{ Consequent } \\
\hline & & \multicolumn{3}{|c|}{$\mathrm{M}(\mathrm{FCS})$} & & \multicolumn{3}{|c|}{$\mathrm{Y}(\mathrm{MS})$} \\
\hline & & Coeff. & $S E$ & $p$ & & Coeff. & $S E$ & $p$ \\
\hline $\mathrm{X}(\mathrm{CON})$ & $a$ & 1.03 & 0.04 & $<0.001$ & $c^{2}$ & 0.09 & 0.06 & 0.15 \\
\hline $\mathrm{M}(\mathrm{FCS})$ & & ------ & $-\cdots--$ & ----- & $b$ & 0.29 & 0.05 & $<0.001$ \\
\hline \multirow[t]{3}{*}{ Constant } & $i_{1}$ & 0.49 & 0.36 & 0.06 & $i_{1}$ & 3.95 & 0.22 & $<0.001$ \\
\hline & & \multicolumn{3}{|c|}{$R^{2}=0.63$} & \multicolumn{4}{|c|}{$R^{2}=0.33$} \\
\hline & & \multicolumn{3}{|c|}{$F(1,315)=544.20, p<0.001$} & \multicolumn{4}{|c|}{$F(2,314)=77.30, p<0.001$} \\
\hline
\end{tabular}

Note. $\mathrm{CON}=$ constructive financial conflict message; FCS = financial communication satisfaction; MS = marital satisfaction. 
$[0.16,0.31], R_{\text {med }}^{2}=0.23,95 \%$ CI $[0.16,0.32]$. Financial communication satisfaction mediated the relationship between destructive financial conflict messages and marital satisfaction (see Table 2).

Parallel to destructive financial conflict messages, the demand-withdraw financial conflict pattern negatively predicted financial communication satisfaction, $a=-1.03,95 \%$ CI $[-1.13,-0.93]$, and financial communication satisfaction positively predicted marital satisfaction, $b=0.23,95 \% \mathrm{CI}[0.16,0.31]$. The indirect effect of the demand-withdraw financial conflict pattern on marital satisfaction was significant, $a b=-0.24,95 \%$ CI $[-0.35,-0.14], \kappa^{2}=0.22,95 \%$ CI [0.13, $0.31], R_{\text {med }}^{2}=0.27,95 \%$ CI $[0.18,0.35]$. The association between the demand-withdraw financial conflict pattern and marital satisfaction was mediated by financial communication satisfaction (see Table 3 ).

Mutual avoidance of financial discussions negatively predicted financial communication satisfaction, $a=-0.80,95 \% \mathrm{CI}[-0.88,-0.71]$, and financial communication satisfaction positively predicted marital satisfaction, $b=0.37,95 \% \mathrm{CI}$

Table 2. Model coefficients for destructive financial conflict messages.

\begin{tabular}{|c|c|c|c|c|c|c|c|c|}
\hline & & \multicolumn{7}{|c|}{ Consequent } \\
\hline \multirow[b]{2}{*}{ Antecedent } & & \multicolumn{3}{|c|}{$\mathrm{M}(\mathrm{FCS})$} & & \multicolumn{3}{|c|}{ Y (MS) } \\
\hline & & Coeff. & $S E$ & $p$ & & Coeff. & $S E$ & $p$ \\
\hline $\mathrm{X}$ (DES) & $a$ & -0.73 & 0.05 & $<0.001$ & $c^{\prime}$ & -0.19 & 0.04 & $<0.001$ \\
\hline M (FCS) & & ----- & ----- & ------ & $b$ & 0.24 & 0.03 & $<0.001$ \\
\hline \multirow[t]{3}{*}{ Constant } & $i_{1}$ & 7.15 & 0.13 & $<0.001$ & $i_{1}$ & 5.16 & 0.27 & $<0.001$ \\
\hline & & \multicolumn{3}{|c|}{$R^{2}=0.41$} & & \multicolumn{3}{|c|}{$R^{2}=0.37$} \\
\hline & & \multicolumn{3}{|c|}{$F(1,315)=217.17, p<0.001$} & & \multicolumn{3}{|c|}{$F(2,314)=91.30, p<0.001$} \\
\hline
\end{tabular}

Note. DES = destructive financial conflict message; FCS = financial communication satisfaction; MS = marital satisfaction.

Table 3. Model coefficients for demand-withdraw financial conflict messages.

\begin{tabular}{|c|c|c|c|c|c|c|c|c|}
\hline \multirow[b]{3}{*}{ Antecedent } & & \multicolumn{7}{|c|}{ Consequent } \\
\hline & & \multicolumn{3}{|c|}{$\mathrm{M}(\mathrm{FCS})$} & & \multicolumn{3}{|c|}{$\mathrm{Y}(\mathrm{MS})$} \\
\hline & & Coeff. & $S E$ & $p$ & & Coeff. & $S E$ & $p$ \\
\hline $\mathrm{X}(\mathrm{DW})$ & $a$ & -1.03 & 0.05 & $<0.001$ & $c^{2}$ & -0.09 & 0.06 & $<0.001$ \\
\hline $\mathrm{M}(\mathrm{FCS})$ & & ----- & ---- & ---- & $b$ & 0.23 & 0.04 & $<0.001$ \\
\hline \multirow[t]{3}{*}{ Constant } & $i_{1}$ & -7.66 & 0.12 & $<0.001$ & $i_{1}$ & 5.26 & 0.34 & $<0.001$ \\
\hline & & \multicolumn{3}{|c|}{$R^{2}=0.58$} & \multicolumn{4}{|c|}{$R^{2}=0.35$} \\
\hline & & \multicolumn{3}{|c|}{$F(1,315)=436.61, p<0.001$} & \multicolumn{4}{|c|}{$F(2,314)=85.53, p<0.001$} \\
\hline
\end{tabular}

Note. $\mathrm{DW}=$ the demand-withdraw financial conflict pattern; FCS = financial communication satisfaction; MS = marital satisfaction. 
$[0.29,0.45]$. The indirect effect of mutual avoidance of financial discussions on marital satisfaction was significant, $a b=-.30,95 \%$ CI $[-0.40,-0.21], \kappa^{2}=0.34$, $95 \%$ CI $[0.25,0.43], R_{\text {med }}^{2}=.14,95 \%$ CI $[0.05,0.25]$. Financial communication satisfaction mediated the association between mutually avoiding financial conflict and marital satisfaction (see Table 4).

These meditational effects were replicated in models including financial wellness and income as covariates, with all four indirect effects remaining significant. Since the influence of the covariates was negligible, the models without covariates are reported in order to provide reliable effect size estimates. $\kappa^{2}$ and $R_{\text {med }}^{2}$ have not yet been generalized to models with covariates (Hayes, 2013).

Table 4. Model coefficients for mutually avoiding financial conflict messages.

\begin{tabular}{|c|c|c|c|c|c|c|c|c|}
\hline \multirow[b]{3}{*}{ Antecedent } & & \multicolumn{7}{|c|}{ Consequent } \\
\hline & & \multicolumn{3}{|c|}{$\mathrm{M}(\mathrm{FCS})$} & & \multicolumn{3}{|c|}{ Y (MS) } \\
\hline & & Coeff. & $S E$ & $p$ & & Coeff. & $S E$ & $p$ \\
\hline $\mathrm{X}(\mathrm{MA})$ & $a$ & -0.80 & 0.04 & $<0.001$ & $c^{2}$ & 0.04 & 0.05 & 0.36 \\
\hline $\mathrm{M}(\mathrm{FCS})$ & & ------ & ----- & ------ & $b$ & 0.37 & 0.04 & $<0.001$ \\
\hline \multirow[t]{3}{*}{ Constant } & $i_{1}$ & 7.21 & 0.11 & $<0.001$ & $i_{1}$ & 3.93 & 0.30 & $<0.001$ \\
\hline & & \multicolumn{3}{|c|}{$R^{2}=0.52$} & \multicolumn{4}{|c|}{$R^{2}=0.33$} \\
\hline & & \multicolumn{3}{|c|}{$F(1,315)=341.19, p<0.001$} & \multicolumn{4}{|c|}{$F(2,314)=76.36, p<0.001$} \\
\hline
\end{tabular}

Note. $\mathrm{MA}=$ mutually avoiding financial conflict; $\mathrm{FCS}$ = financial communication satisfaction; $\mathrm{MS}=$ marital satisfaction.

\section{Discussion}

The current study contributes to understanding how financial harmony (or lack thereof) is related to the financial conflict messages communicated during financial disagreements and which financial conflict messages contribute to, or detract from, financial communication satisfaction and marital satisfaction. Unlike prior studies of marital conflict, the current investigation focused specifically on how married individuals' communication about finances is related to marital satisfaction. This permits more precise inferences about the role of financial conflict in marriage. The current study also offers an empirical explanation for how financial conflict communication influences marital satisfaction. Specifically, financial communication satisfaction carries the influence of financial conflict messages on marital satisfaction.

\subsection{Financial Harmony}

Financial harmony plays an important role in the financial conflict messages communicated when financial disputes occur. Our findings suggest financial harmony predisposes people to communicate in certain ways due to their expectations of how their spouse will handle financial issues. When individuals 
perceive that their financial beliefs are similar to their partner's, they are more likely to communicate by openly and calmly discussing financial concerns because they are likely to be less worried about a hostile argument arising. However, when a spouse already knows that they and their marital partner disagree about how to handle financial concerns, they are more likely to communicate dysfunctionally (i.e., destructive, demand-withdraw, mutual avoiding), which aggravates their disparities, triggering more dysfunctional communication. Consequently, the financial issue is left unresolved and resentments are likely to linger.

\subsection{Marital Satisfaction and Financial Communication Satisfaction}

Parallel to previous research on conflict messages and marital satisfaction, the current study's results suggest that constructive financial conflict messages are positively associated with marital satisfaction, while destructive financial conflict messages and the demand-withdraw financial conflict pattern are both negatively related to marital satisfaction. Regardless of income and financial wellness, participants in this study rated their marital satisfaction higher when they perceived their financial conversations as proactively discussing financial issues compared to those who perceived their financial communicative pattern to be characterized as the demand-withdraw pattern or both partners consistently blaming, accusing, or criticizing each other.

The current study also predicted that financial conflict messages would be associated with financial communication satisfaction. Supporting the hypotheses, constructive financial conflict messages and marital satisfaction were both positively related to financial communication satisfaction. Destructive financial conflict messages and the demand-withdraw financial conflict pattern were negatively related to financial communication satisfaction. These effects were robust even when controlling for financial wellness and income. When partners are compromising with each other over the financial issue, in addition to openly discussing the financial concern, they are likely to feel more pleased about the interaction with their spouse. When partners are hostile, threatening, shouting at each other regarding the financial dispute, spouses are more likely to be frustrated by the interaction and disappointed with the outcome. In similar fashion, when one spouse is demanding change in the other spouse, and the other spouse avoids the financial issue, the demanding spouse is probably more dissatisfied that the avoiding spouse did not change their stance on the financial concern. The avoiding spouse is likely to harbor resentment and feel annoyance over being continually nagged about the financial issue under dispute.

Financial communication satisfaction mediated the relationship between the each of the four financial conflict messages and marital satisfaction. This makes intuitive sense and resonates with previous conflict research (e.g., Canary \& Cupach, 1988). If couples are acknowledging the financial conflict and discussing the issue then they are more likely to be satisfied with the outcome of the finan- 
cial conflict, which in turn, makes them more satisfied in their marriage. If couples are blaming, accusing, or criticizing each other during the financial discussion, they are more likely to be dissatisfied with the financial communication event, which ultimately erodes their marital satisfaction.

Of particular interest are the outcomes of mutually avoiding financial conversations on financial harmony, financial communication satisfaction, and marital satisfaction. Scholars have previously documented equivocal findings in terms of avoiding conflict and marital satisfaction. There are situations in which avoidance is a benefit for the relationship and situations where avoidance is detrimental (Roloff \& Ifert, 2000). However, data from the current study suggest that when it comes to marital financial issues, routine mutual avoidance of financial conflict is negatively related to financial harmony, financial communication satisfaction, and marital satisfaction. Avoiding financial conflict does not appear to be a reflection of spouses being in sync with each other regarding financial matters. It is more of a reflection of financial disharmony.

The current findings found data consistent with the idea that mutually avoiding financial conflict is associated with financial communication satisfaction and marital satisfaction in ways similar to destructive financial conflict messages. One explanation for this finding lies in the importance of money in marital relationships. Avoidance is functional when the topic is of little importance to both individuals (Roloff \& Ifert, 2000). One thing that makes financial issues in a marriage important is the ability of one partner to make a unilateral decision that has the potential to substantially affect both spouses (Stanley, Markman, \& Whitton, 2002). Although avoiding a discussion in a particular episode of financial conflict may be desirable, mutual avoidance as a chronic pattern of managing financial issues seems to be inimical to marital relationships. Because of its central importance in marriage, finances may require occasional open discussion for marital maintenance, except in cases where all aspects of both partner's finances are independent of one another.

The current findings suggest some important implications for both married individuals and marriage counselors. First, partners must recognize that financial issues are an intrinsic aspect of marital relationships. Decisions and actions regarding spending, saving, investing, and borrowing are unavoidable and they constitute part of the interdependence of married partners. Such issues can lead to conflict, but that conflict is manageable as long as discussions retain a problem-solving tone. Second, although money issues can be difficult to discuss, they should not be ignored. Our evidence suggests that mutually avoiding financial discussions, as well as one partner's avoidance of another partner's attempt to discuss financial issues, are associated with marital dissatisfaction. These patterns of communication seem to create uncertainty and resentment that result in dissatisfaction with financial communication. Although finances can represent a significant stressor in marriage, collaborative discussion can ease some of the financial pressure on the marriage. 


\section{Limitations and Additional Avenues of Research}

The implications just noted are tempered by the limitations of our data. One important limitation is that our method of participant recruitment yielded a somewhat homogeneous sample. Participants were predominately white women, middle-class, and satisfied with their marriage. Additionally, participants in this sample had a relatively high median household income, falling between $\$ 100,000$ to $\$ 149,000$. Perhaps due to a self-selection bias, individuals less satisfied within their marriages and less satisfied with finances are underrepresented in our sample. This limits the generalizability of our findings. Additional research with a more diverse sample is needed to verify the replicability and validity of conclusions drawn here.

The typical limitations of cross-sectional data and retrospective self-reports apply to our study. Shared method variance, sentiment override, and memory biases could be inflating the observed associations among our variables. In addition, we were not able to distribute surveys to both spouses within the same marriage. Future research should try to as it would allow scholars to see if both spouses perceived their financial communication patterns similarly. One way researchers could get both spouses opinions is by conducting a diary study. This should consist of both marital partners describing their financial discussions, tracking their financial communication patterns and then rating their financial communication satisfaction and marital satisfaction right after engaging in the financial discussion. By doing this, scholars could understand the various types of financial discussions that occur in marriages (e.g., savings, debt, investing, spending) to get at the heart of spousal financial dissimilarity. Perhaps some spouses are in sync with regards to investing and they communicate constructively. That same marital couple could disagree about spending, leading them to communicate in dysfunctional ways. Maybe some financial topics are more detrimental to a marriage then others. Furthermore, diary studies could minimize the memory biases that attend retrospective self-reports.

\section{Conclusion}

The current findings suggest that even before engaging in a financial conversation with a spouse, the perception of financial (dis) harmony will predispose a spouse to communicate in a certain way based on their expectations of how their partner would handle the financial issue in question. The different financial conflict messages are important factors of marital satisfaction regardless of one's financial wellness or one's income. Communicating constructively about financial issues within a marriage is likely to act as a buffer against the negative relational consequences of financial conflict.

\section{References}

Archuleta, K. L., Britt, S. L., Tonn, T. J., \& Grable, J. E. (2011). Financial Satisfaction and Financial Stressors in Marital Satisfaction. Psychological Reports, 108, 563-576. 
https://doi.org/10.2466/07.21.PR0.108.2.563-576

Atwood, J. D. (2012). Couples and Money: The Last Taboo. The American Journal of Family Therapy, 40, 1-19. https://doi.org/10.1080/01926187.2011.600674

Blumstein, P., \& Schwartz, P. (1983). American Couples: Money, Work, Sex. New York, NY: Pocket Books.

Britt, S. L., Huston, S., \& Durband, D. B. (2010). The Determinants of Money Arguments between Spouses. Journal of Financial Therapy, 1, 42-60. https://doi.org/10.4148/jft.v1i1.253

Canary, D. J., \& Cupach, W. R. (1988). Relational and Episodic Characteristics Associated with Conflict Tactics. Journal of Social and Personal Relationships, 5, 305-325. https://doi.org/10.1177/0265407588053003

Canary, D. J., Cupach, W. R., \& Serpe, R. T. (2001). A Competence-Based Approach to Examining Interpersonal Conflict: Test of a Longitudinal Model. Communication Research, 28, 79-104. https://doi.org/10.1177/009365001028001003

Canary, D. J., \& Spitzberg, B. H. (1989). A Model of the Perceived Competence of Conflict Strategies. Human Communication Research, 15, 630-649. https://doi.org/10.1111/j.1468-2958.1989.tb00202.x

Christensen, A., \& Heavey, C. L. (1990). Gender and Social Structure in the Demand/Withdraw Pattern of Marital Conflict. Journal of Personality and Social Psychology, 59, 73-81. https://doi.org/10.1037/0022-3514.59.1.73

Christensen, A., \& Shenk, J. L. (1991). Communication, Conflict, and Psychological Distance in Nondistressed, Clinic, and Divorcing Couples. Journal of Consulting and Clinical Psychology, 59, 458-462. https://doi.org/10.1037/0022-006X.59.3.458

Cupach, W. R. (2015). Communication Competence in the Management of Conflict. In A. F. Hannawa, \& B. H. Spitzberg (Eds.), Handbook of Communication Science (Vol. 22, pp. 341-366). Berlin: De Gruyter Mouton. https://doi.org/10.1515/9783110317459-015

Deutsch, M. (1973). The Resolution of Conflict: Constructive and Destructive Processes. London: Yale University Press.

Dew, J., Britt, S., \& Huston, S. (2012). Examining the Relationship between Financial Issues and Divorce. Family Relations, 61, 615-628. https://doi.org/10.1111/j.1741-3729.2012.00715.x

Dew, J., \& Dakin, J. (2011). Financial Disagreements and Marital Conflict Tactics. Journal of Financial Therapy, 2, 23-42. https://doi.org/10.4148/jft.v2i1.1414

Fairchild, A. J., MacKinnon, D. P., Toborga, M. P., \& Taylor, A. B. (2009). R-Squared Effect-Size Measures for Mediation Analysis. Behavior Research Methods, 41, 486-498. https://doi.org/10.3758/BRM.41.2.486

Futris, T. G., Campbell, K., Nielsen, R. B., \& Burwell, S. R. (2010). The Communication Patterns Questionnaire-Short Form: A Review and Assessment. The Family Journal, 18, 275-287. https://doi.org/10.1177/1066480710370758

Gottman, J. M. (1979). Marital Interaction: Experimental Investigations. New York, NY: Academic Press.

Gottman, J. M. (1994). What Predicts Divorce? The Relationship between Marital Processes and Marital Outcomes. Hillsdale, NJ: Lawrence Erlbaum.

Hayes, A. F. (2009). Beyond Barron and Kenny: Statistical Mediation Analysis in the New Millennium. Communication Monographs, 76, 408-420.

https://doi.org/10.1080/03637750903310360 
Hayes, A. F. (2013). Introduction to Mediation, Moderation, and Conditional Process Analysis: A Regression-Based Approach. New York, NY: Guilford Press.

Hecht, M., Sereno, K., \& Spitzberg, B. H. (1984). Communication Satisfaction and Satisfaction with Self and Other: The Relevance of Relationship Level and Topic Level. Personality and Social Psychology, 10, 376-384. https://doi.org/10.1177/0146167284103005

Hendrick, S. S. (1988). A Generic Measure of Relationship Satisfaction. Journal of Marriage and the Family, 50, 93-98. https://doi.org/10.2307/352430

Newton, D. A., \& Burgoon, J. K. (1990). Nonverbal Conflict Behaviors: Functions, Strategies, and Tactics. In D. D. Cahn (Ed.), Intimates in Conflict: A Communication Perspective (pp. 77-104). Hillsdale, NJ: Lawrence Erlbaum.

Oggins, J. (2003). Topics of Marital Disagreement among African-American and Euro-American Newlyweds. Psychological Reports, 92, 419-425. https://doi.org/10.2466/pr0.2003.92.2.419

Papp, L. M., Cummings, E. M., \& Goeke-Morey, M. C. (2009). For Richer, for Poorer: Money as a Topic of Marital Conflict in the Home. Family Relations, 58, 91-103. https://doi.org/10.1111/j.1741-3729.2008.00537.x

Papp, L. M., Kouros, C. D., \& Cummings, E. M. (2009). Demand-Withdraw Patterns in Marital Conflict in the Home. Personal Relationships, 16, 285-300. https://doi.org/10.1111/j.1475-6811.2009.01223.x

Prawitz, A. D., Garman, T., Sorhaindo, B., O’Neil, B., Kim, J., \& Drentea, P. (2006). InCharge Financial Distress/Financial Well-Being Scale: Development, Administration, and Score Interpretation. Financial Counseling and Planning, 17, 34-50. http://papers.ssrn.com/sol3/papers.cfm?abstract_id=2239338

Preacher, K. J., \& Hayes, A. F. (2008). Contemporary Approaches to Assessing Mediation in Communication Research. In A. F. Hayes, M. D. Slater, \& L. Synder (Eds.), The Sage Sourcebook of Advanced Data Analysis Methods for Communication Research (pp. 13-54). Thousand Oaks, CA: Sage. https://doi.org/10.4135/9781452272054.n2

Preacher, K. J., \& Kelley, K. (2011). Effect Size Measures for Mediation Models: Quantitative Strategies for Communicating Indirect Effects. Psychological Methods, 16, 93-115. https://doi.org/10.1037/a0022658

Putnam, L. L., \& Wilson, C. E. (1982). Communication Strategies in Organizational Conflicts: Reliability and Validity of a Measurement Scale. In M. Burgoon (Ed.), Communication Yearbook 6 (pp. 629-652). Beverly Hills, CA: Sage.

Rick, S. I., Small, D. A., \& Finkel, E. J. (2011). Fatal (Fiscal) Attraction: Spendthrifts and Tightwads in Marriage. Journal of Marketing Research, 48, 228-237. https://doi.org/10.1509/jmkr.48.2.228

Roloff, M. E. (1976). Communication Strategies, Relationships, and Relational Change. In G. R. Miller (Ed.), Explorations in Interpersonal Communication (pp. 173-195). Beverly Hills, CA: Sage.

Roloff, M. E., \& Ifert, D. E. (2000). Conflict Management through Avoidance: Withholding Complaints, Suppressing Arguments, and Declaring Topics Taboo. In S. Petronio (Ed.), Balancing the Secrets of Private Disclosures (pp. 151-179). Mahwah, NJ: Lawrence Erlbaum.

Romo, L. K. (2011). Money Talks: Revealing and Concealing Financial Information in Families. Journal of Family Communication, 11, 264-281.

https://doi.org/10.1080/15267431.2010.544634

Schrodt, P., Witt, P. L., \& Shimkowski, J. R. (2014). A Meta-Analytical Review of the Demand/Withdraw Pattern of Interaction and Its Associations with Individual, Relation- 
al, and Communicative Outcomes. Communication Monographs, 8, 28-58. https://doi.org/10.1080/03637751.2013.813632

Sillars, A. L. (1980). Attributions and Communication in Roommate Conflict. Communication Monographs, 47, 180-200. https://doi.org/10.1080/03637758009376031

Sillars, A. L., Coletti, S. F., Parry, D., \& Rogers, M. A. (1982). Coding Verbal Conflict Tactics: Nonverbal and Perceptual Correlates of the "Avoidance-Distributive-Integrative" Distinction. Human Communication Research, 9, 83-95. https://doi.org/10.1111/j.1468-2958.1982.tb00685.x

Smith, L., Heaven, P. C. L., \& Ciarrochi, J. (2008). Trait Emotional Intelligence, Conflict Communication Patterns, and Relationship Satisfaction. Personality and Individual Differences, 44, 1314-1325. https://doi.org/10.1016/j.paid.2007.11.024

Stanley, S. M., Markman, H. J., \& Whitton, S. W. (2002). Communication, Conflict, and Commitment: Insights on the Foundations of Relationship Success from a National Survey. Family Process, 41, 659-675. https://doi.org/10.1111/j.1545-5300.2002.00659.x

Ting-Toomey, S. (1983). Coding Conversation between Intimates: A Validation Study of the Intimate Negotiation Coding System (INCS). Communication Quarterly, 31, 68-77. https://doi.org/10.1080/01463378309369488

Wilmarth, M. J., Nielsen, R. B., \& Futris, T. G. (2014). Financial Wellness and Relationship Satisfaction: Does Communication Mediate? Family and Consumer Science Research, 43, 131-144. https://doi.org/10.1111/fcsr.12092 